on the economics of nuclear power by Lane is unfortunately only pertinent to the United States and so is of limited interest.

Two chemical contributions, technetium and astatine chemistry by Anders and solvent extraction by Freiser and Morrison record facts and techniques hitherto scattered through project reports. Three radiobiological articles as usual complete the volume : vertebrate radiobiology (embryology) by Rugh, biochemical effects of radiation by Ord and Stocken, and cellular radiobiology by Atwood. These demonstrate the continuing advance in this broad field.

E. B. PAUI

\section{MASS, LENGTH AND TIME}

An Introduction to the Physics of Mass, Length and Time

By Prof. Norman Feather. (Science and Mathematics Texts, No. 1.) Pp. ix +358 . (Edinburgh : At the University Press, 1959. Distributed by Thomas Nelson and Sons, Ltd.) 18s. net.

THE early part of this excellent book deals with the history and philosophy of fundamental measurement, together with the practical problems of defining, preserving and reproducing standards. It is a fascinating story, told with scholarship and skill. The rest presents the usual matter of a course of Advancod Lovel General Certificate of Education standard in mechanics and general physies in an unpretentious and thoughtfully penetrating way.

Prof. Feather has, as he puts it, "disdained to use the calculus". This is not really hauteur, but a means of enforcing a pace of slow and careful reading ; the modern student is all too fluent, and can use it slickly without thinking. At the same time, it can be argued that the moment you introduce the concepts of velocity and acceleration, draw a continuous graph, or use moment of inertia or impulse, you are really using the calculus, though not its notation. You do not remove the tune from a piece of music by writing it in tonic sol-fa. The author does unbend a little in the last chapter, in fact. But if he had not himself directed attention to this point specially, it would not have called for comment.

Newtonian mechanics, and what John Cox called "the winning of the principles", are clearly explained, with emphasis on the importance of the third law. A whole chapter is devoted to potential energy, which is really a much deeper matter than the usual elementary books suggest. Gravitation is treated historically, starting with the genesis of Newton's law and ending with the design problems of apparatus of the type devised by Cavendish. For the rest, the discussion of the struggles of Archimedes with the law of the lever, and that of surface tension in terms of interfacial energy and molecular attraction, are among the many stimulating treatments.

The general outlook of the book is more like that of "Norman Campbell" or "Pearson" or "Pohl" than that of the ordinary text-book, though teachers of sixth-form physics would do well to consider its possibilities for class use, and it would certainly be a valuable book for students to read. It puts the inquiring approach of the scientist before the factual knowledge of the examinee. The liveliness and effortless dry humour, fortified by a wealth of historical detail, make it very pleasant to read, and the publishers have produced it most attractively.

G. R. NOAKES

\section{SPOTTING KETOSTEROIDS}

\section{Oxosteroids}

The Use of Phenolic Hydrazides for Detection, Characterization and Estimation. By Bernard Camber. Pp. viii +79. (London : H. K. Lowis and Co., Ltd., 1960.) 12s. 6 d. net.

$\mathrm{W}$ HAT we used to call 'ketosteroids' can usually be estimated by some modification of the Zimmerman reaction, and the colours given by different ketosteroids with alkali and $m$-dinitrobenzene have long been used in 'spotting' on paper chromatograms and in the test-tube as a rough guide to the position of tho keto group in the steroid molecule in unidentified substances.

Dr. Camber is a medically trained man with an interest in chemistry. His little book is an account of his search to find a hydrazine derivative which would condense with known physiologically important ketosteroids to give hydrazones which could be used to provide a quantitative method replacing the Zimmerman procedure, to identify individual ketosteroids as spots after chromatography on papor and in the histology of steroid-containing tissue. After forty-one pages, he arrives at salicyclic acid hydrazide (salicoyl hydrazine), which readily gives, with ketosteroids, hydrazones that can be used for these purposes. The early part of the book has a short account of somo methods used for steroid estimations and also details of Dr. Camber's lessuseful derivatives of hydrazine. His finally chosen reagent is valuable, although the quantitative mothods have not received exhaustive testing with urines and only preliminary histological work has been done. 'Spotting' on paper chromatograms is, however, well developed, giving useful information about steroids separated. The author is an ingenious experimenter, as is shown, for example, by his tochnique of spot testing in 'Cellophane'. It is also clear that he has enjoyed doing and expounding his work. He is perfectly frank in not pretending that his reagont is porfect for the purposes suggested: he gives details and obviously would prefer those interested to try it for themselves.

Workers in this field will be willing to buy this book for the 'know-how' which it contains. Full experimental details are given for all methods, qualitative and quantitative, recommended, including the preparation of a sufficiently pure sample of salicy. clic acid hydrazide.

G. A. D. Haslewood

\section{STUDIES IN MARINE PHYSICS}

\section{The Gulf Stream}

A Physical and Dynamical Description. By Henry Stommol. Pp. xiii +202. (Berkeley and Los Angeles : University of California Press ; London : Cambridge University Press, 1958.) 45s. net.

$\mathrm{N}$ Europe, at least, marine biologists vastly out1 number marine physicists, and one of the things that has prevented physicists from becoming interested in the oceans is the difficulty of finding concise accounts of the problems written in the precise terms to which they are accustomed when dealing with modern science. Dr. Stommel is one of the leaders of a strong theoretical group in the eastern United States, who has spent many years studying the Gulf Stream, and his book gives a clear and 